\title{
Our Surgical Heritage: Walter Edward Dandy_-The Founding Father of Neurosurgery
}

Rao R Ivatury ${ }^{1} \odot$

\author{
Abstract \\ Aim and objective: Pay homage to the Founding Father of Neurosurgery. \\ Materials and methods: Literature review. \\ Background: Walter Dandy was a neurosurgeon from Johns Hopkins Hospital in Baltimore, USA. Trained by Harvey Cushing, another founding \\ father of the specialty, Dandy excelled in his technical ability and became the leading neurosurgeon at Hopkins till death at 60 in 1946 . His \\ contributions to the field of neurosurgery include 160 articles and five books, among them a classic text on neurosurgery, "Surgery of the Brain" \\ (1935) and many original operative procedures. \\ Clinical significance: Surgical heritage review. \\ Keywords: Brain, Decompressive craniectomy, Neurosurgery. \\ Panamerican Journal of Trauma, Critical Care \& Emergency Surgery (2021): 10.5005/jp-journals-10030-1352
}

Walter Edward Dandy, (April 6, 1886-April 19, 1946), (Fig. 1), a brilliant surgeon, was considered one of the founding fathers of neurosurgery. ${ }^{1-7}$ He was born to immigrants, his father from Lancashire and his mother from Ireland. He attended the University of Missouri and then joined the Johns Hopkins School of Medicine as a second-year student after skipping first year from accumulated credits. Even though he had a chance to take on Rhodes' scholarship in Oxford, he stayed and graduated from Johns Hopkins School of Medicine in 1910 at the age of 24. His brilliance caught the attention of Harvey W Cushing, then an assistant resident with the "Professor" (William Steward Halstead) and already famous as a brain surgeon. ${ }^{8}$ Cushing appointed him to the Hunterian Laboratory of Experimental surgery ("the doghouse") from 1910 -1911. Dandy exhibited his abilities in anatomy when he published in the American Journal of Anatomy the dissection of: "A Human Embryo With Seven Pairs of Somites about 2 mm in Length' 5 months before his graduation." ${ }^{9}$

Dandy continued his work in the Hunterian Laboratory on canine and feline pituitary bodies, earning a Master of Arts degree.

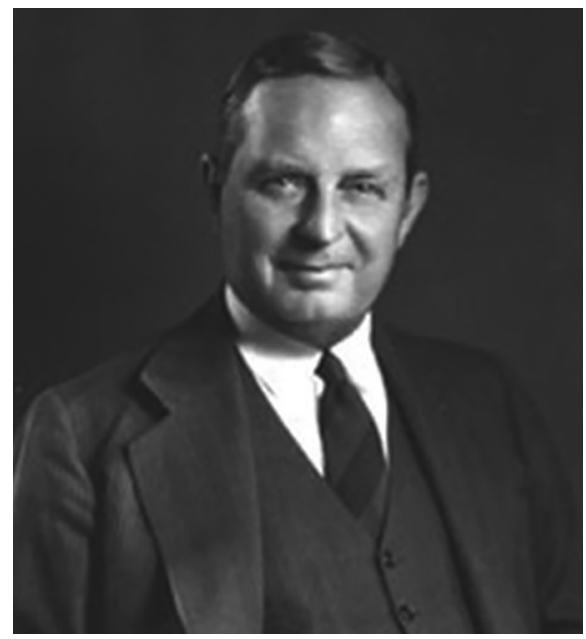

Fig. 1: Walter Edward Dandy
${ }^{1}$ Department of Surgery, Virginia Commonwealth University, Richmond, Virginia, United States

Corresponding Author: Rao R Ivatury, Department of Surgery, Virginia Commonwealth University, Richmond, Virginia, United States, Phone: +1 804-651-1575, e-mail: raoivatury@gmail.com

How to cite this article: Ivatury RR. Our Surgical Heritage: Walter Edward Dandy-The Founding Father of Neurosurgery. Panam J Trauma Crit Care Emerg Surg 2021;10(3):121-125.

Source of support: $\mathrm{Nil}$

Conflict of interest: None

His foundation for his future success in pituitary surgery was set. The laboratory, unfortunately, also gave him a taste of Cushing's caustic temper.

Dandy decided to join the Johns Hopkins Hospital surgical house staff for one year as Cushing's Assistant Resident (1911-1912) and completed his general surgery residency under Professor Halsted in 1918. In 1913, Dandy came under the tutelage of the pediatrician, Kenneth Daniel Blackfan (1883-1951) famous for his syndrome of congenital pure red cell aplasia. Together, they described the pathogenesis and management of hydrocephalus, its two types and the physiology of cerebrospinal fluid ${ }^{1-7}$ Dandy was only 27 years of age. Duly impressed, Halstead called Dandy the most brilliant pupil he ever had. He also gave a wrong forecast: "Dandy will never do anything equal to this again. Few men make more than one great contribution to medicine." ${ }^{10}$ Dandy's astounding list of contributions in neuroscience would continue till his death (Table 1). Dandy published over 160 articles and five books in neurosurgery.

\section{Dandy, the Superb Surgeon and his "BraIN TEAM"}

Dandy's "Brain Team" excelled in both patient care as well as in training future neurosurgeons. The team had a few residents of neurosurgery and some from general surgery residency (which was for 8 years at the time of Halsted), a dedicated scrub

(c) The Author(s). 2021 Open Access This article is distributed under the terms of the Creative Commons Attribution 4.0 International License (https://creativecommons. org/licenses/by-nc/4.0/), which permits unrestricted use, distribution, and non-commercial reproduction in any medium, provided you give appropriate credit to the original author(s) and the source, provide a link to the Creative Commons license, and indicate if changes were made. The Creative Commons Public Domain Dedication waiver (http://creativecommons.org/publicdomain/zero/1.0/) applies to the data made available in this article, unless otherwise stated. 
Table 1: Dandy's contributions

At the age of 27

Dandy (in conjunction with Blackfan) published the first series of now classic papers, ten, on hydrocephalus and the circulation of the cerebrospinal fluid.

1918 While a resident in

1919 training

He was nominated for the Nobel Prize in 1933. Ventriculography allowed neurosurgeons for the first time to visualize brain lesions on $\mathrm{x}$-rays. Pneumoencephalography, by injecting air into the subarachnoid space in the spinal canal, avoided making burr-holes in the skull for injecting air. Samuel J Crowe described it as "the greatest single contribution ever made to brain surgery." (Fox 1984, p. 43) Gilbert Horrax stated: "The importance of this diagnostic method, ... for the more accurate localization of many growths whose situation could not be ascertained with absolute exactness, can hardly be overemphasized. It brought immediately into the operable field at least one third more brain tumors than could be diagnosed and localized previously by the most refined neurological methods." (Fox 1984, p.45)

1919 Pneumoperitoneum

First to describe pneumoperitoneum on CXR. On 3 Januray 1917, a patient whose abdomen was about to be explored by Dandy for intestinal perforation chanced to have a chest $x$-ray taken on the way to the operating The upper abdomen was included in the x-ray.

Air was clearly visible under the diaphragm. Operation confirmed the presence of intraperitoneal air, as well as the perforated typhoid ulcer through which it had escaped.

It is of interest that this was the very roentgenogram that originally suggested to Dandy the use of air to outline the cerebral ventricles!

The pituitary

The intradural approach was devised by Heuer, Dandy's predecessor as resident surgeon. Dandy subsequently modified it by using a small frontal flap with concealed skin incision and by lowering the vertex of the head as soon as the dura was opened in order to obtain better exposure with less retraction of the frontal lobe.

1921 Pineal: surgical approach

The posterior $2 \mathrm{~cm}$ of the corpus callosum were divided in the midline, the "anemic area" in the roof of the third ventricle between the small veins of Galen was entered and the pineal, then clearly visible, removed with cupped forceps. Faster and with little bleeding.

Described an adaptation of the canine pinealectomy operation to man and recorded three cases, one with a tuberculoma.

1922 Acoustic neuroma

Replaced Cushing's method of enucleation of the tumor by total extirpation of the tumor. He later reported that in his last 41 cases of total extirpation by a unilateral approach, he had reduced his mortality to $2.4 \%$. This was before the use of the surgical microscope!

1922 Cerebral ventriculoscopy

1922 "Hemispherectomy"

Use of endoscopy for treatment of hydrocephalus.

1925 Trigeminal neuralgia

For malignant tumors.

Existing approach had several adverse effects: facial palsies, the corneal ulcers, and hemiplegia. Dandy approached the trigeminal nerve through the posterior fossa. Over the next 20 years Dandy performed well over 500 partial or total divisions of the sensory root by this method with less than $1 \%$ mortality. He also supported total division to prevent recurrence of symptoms.

1926 Pneumocephalus Gave a comprehensive summary of this condition and established that closure of the dural opening was highly desirable and readily feasible.

1927 Tic douloureux

1928 Meniere's disease

Recorded the first two cases of intracranial division of the glossopharyngeal nerve for tic.

By 1928 Dandy was able to report nine operations for "persistent aural vertigo" and again for "persistent tinnitus," all successful. During his lifetime he did a total of 692 operations for Meniere's disease with only two fatalities and both of these were due to infection.

Published "Venous Abnormalities and Angiomas of the Brain." In the same year he recorded eight cases of congenital arteriovenous aneurysm. Except for one who had a fatal hemorrhage, all survived.

Combined his operations for fifth and ninth nerves division, for malignancies of the face, mouth, and throat for pain relief.

1930 Neurophysiological observations

1934

Recorded the first removal in man of the right cerebral

First isolated a carotid-cavernous fistula. It was a prelude to his great work on berry aneurysm of the circle of Willis. a silver clip. Recorded the cure of 20 out of 36 such lesions at operation. Only one operative death.

Classic monograph "Intracranial Arterial Aneurysms". He documented 133 aneurysms verified by operation or autopsy.

Surgery of the Brain. A monograph from Chapter 12 of Lewis' Practice of Surgery.

Miscellaneous epilepsy; Scaphycephaly; Resection of the longitudinal sinus; Ligation of the internal carotid artery.
Reported two cases of $L 3$ disc extrusion with back pain, bilateral sciatic pain, and cauda equina syndrome. A myelogram demonstrated a complete block just above the $L 3$ disc. Dandy operated on both patients, removed the fragments of disc, and both patients experienced excellent relief of pain. Operated upon more than 2,000 patients with herniated lumbar discs without preoperative myelography.

hemisphere-minus the basal ganglia-with "No appreciable disturbance; a bilateral frontal lobectomy with similar results, left occipital lobe or even the left temporal lobe removal was not followed by loss of intelligence".

First cured an internal carotid posterior communicating artery aneurysm by occluding the neck of the aneurysm with

A splendid monograph on "Orbital Tumors." Reported on 24 orbital tumors, 19 of which had intracranial extensions. Cysts of the septum pellucidum and cavum vergae; Spasmodic torticollis; Intermittent exophthalmos; Experimental 
and assistant scrub nurse, a circulating nurse, a full-time nurse anesthetist, a part-time nurse anesthetist, a full-time orderly and Dandy's secretary. Neurologists, neuro-ophthalmologists, and neuro-otologists were frequently consulted and considered ex officio members of the Brain Team. ${ }^{4}$ Another constant member of the Brain Team was Dorcas Hager, a medical illustrator hired by Dandy at his personal expense. She would position herself behind Dandy and draw masterfully his operations in great anatomic detail. Many of these sketches would accompany Dandy's publications. Dandy actually made her write a chapter on the anatomy of the circle of Willis in his next to last major publication "Intracranial arterial aneurysms.. ${ }^{11}$

Sherman, ${ }^{4}$ one of Dandy's residents, described in detail the terrific efficiency of the Brain team's operating routine, performing a high volume of operations (more than 1,000) per year. In a novel practice of the day, the team also followed these patients, significantly improving outcomes and decreasing mortality. "In this panorama," ${ }^{\prime \prime}$ Dandy introduced several innovative surgical techniques with great success. He also devised the first postoperative recovery room, the forerunner of the modern-day intensive care unit.

Sherman also detailed the grueling routine of Dandy's resident staff:".....After surgery, which usually ended between 3 and 5 pm, Dandy made rounds with the residents. The residents examined new patients and were almost always able to have them ready for surgery in the morning. .......Meanwhile, any head trauma cases in the emergency room had to be seen promptly and again 2 hours post trauma in order to detect the possibility of a rapidly growing epidural hematoma. Patients on other services had to be seen when neurosurgical consultations were requested. Any patients who had undergone brain surgery that day also had to be seen at $2 \mathrm{am}$ to assess for evidence of postoperative bleeding or severe edema....... because at 3 am the operating room staff went home, and thereafter it would take too long to reassemble them if the patient needed to return to the operating room.....At all levels of training ..... each resident was on duty 24 hours every day for 50 weeks each year, with 2 weeks off for vacation..... appointments were for 1 year only. There was no contract or written agreement of any sort..... ${ }^{4}$ During these years Dandy was operating 5 full days per week. Each resident was constantly on duty for 50 weeks out of the year, being allowed 2 weeks of vacation. There were no nights or weekends off. When the service was light during Dandy's vacation, one resident could leave the hospital for 2 or 3 hours, but no longer. I spent as much as 3 months at a time without leaving the hospital. Luckily, we had a barbershop in the hospital. When I was away, Otenasek (Chief Resident) lost nearly 1 pound of weight per day, and when Otenasek was away, I lost the same amount, because one resident had to do the work of two and did not have time for three meals each day." ${ }^{4}$

\section{Dandy, a Gifted Clinician}

Dandy was also a brilliant clinician. There were many tales of his diagnostic acumen. One day, an anaesthetized patient was presented before him. After performing virtually a cursory examination, he reached the diagnosis of a cerebral abscess and recommended immediate removal of the offending purulent material in the brain. The patient survived, and when his residents asked him about the secret of his magical diagnosis, he commented, "Dear Colleague, God must have whispered in my ear." In another instance, ${ }^{12}$ after several physicians examined a patient without making the diagnosis, Dandy stood at the foot of the bed, talked to the patient for a few minutes and then stated he would take out the tumor the following day, upsetting everyone present. Dandy then explained that the patient did not blink with his left eye, suggesting nerve paralysis from an acoustic tumor. He was proven correct at surgery the following morning. ${ }^{12}$ Sherman et al. ${ }^{4}$ recalled that once on the basis of a patient's history of Jacksonian seizures starting in the left index finger, Dandy explored the patient's right motor strip in the face of normal findings on ventriculography. He found a tiny surface lesion, which proved to be a glioblastoma multiforme. Its removal, with a margin of normal tissue, left the patient alive and well 8 years later.

\section{Dandy the Man ${ }^{4}$}

Dandy loved his students and was generous in nature. He was extremely devoted to his patients and even used to see patients free of charge. At times, he would pay for patients who cannot afford to come from out of town to see him for treatment. However, he had a reputation to be brusque and unsympathetic toward his colleagues and residents. He had little control over his temper. There were instances of firing assistant residents, scolding personnel, and occasionally throwing an instrument. But, Sherman felt, Dandy cared deeply for his residents' welfare, "although not about how hard we worked."

\section{Cushing-Dandy Controversy $13-15,16$}

A profound competition between Cushing, the gifted master and Dandy, his gifted student ensued by 1910 . Dandy was able to boast to his parents he had "stumped" the master himself in reaching the aqueducts of Silvius without killing the dog, a procedure Cushing had considered impossible.

Dandy's success with a young English sailor with severe epileptic seizures added to the jealousy of Cushing in 1912. Cushing considered the case inoperable but allowed Dandy to try it. In one of Dandy's first operations, he performed a decompression and spent two hours removing all the adhesions he could find clinging to the brain. The sailor recovered and Dandy's triumph spread quickly around the hospital. ${ }^{6}$

Shortly before Cushing was to leave Hopkins for Peter Brigham Hospital in Boston, he came to the Hunterian Laboratory and asked Dandy to show him the results on experiments with hydrocephalus. When Dandy did so, Cushing put it in a box of materials to take to Boston with him. Dandy took his work out of Cushing's box and told Cushing that the material was his and it was going to stay with him. Cushing then remarked that the work probably did not amount to anything anyhow. Cushing left for a 6 weeks vacation before he left for Boston with no word whether Dandy would be accompanying him or not. Dandy was left without a residency position; Halsted having left already for the summer. Smith, the hospital superintendent kindly gave Dandy a room to stay. On Halsted's return, he was given a job as an assistant resident.

During Cushing's absence, Dandy performed 11 brain surgeries, including his first pituitary surgery on July 13, 1912. He wrote about it proudly to his parents: "had a bully week as far as operations are concerned, and did also one hypophysis, Cushing's hardest and most delicate operation. Imagine Cushing looking at me in resentment and disdain when he finds I have done a hypophysis operation and got away with it. The men looked at me in amazement when I posted the operation. That was something none but almighty Cushing would think of doing." ${ }^{6}$

When Dandy presented before the Neurological association his innovation of ventriculography, Cushing was highly critical of it and 
even challenged Dandy's statistics regarding the results. ${ }^{16}$ Dandy was shocked by Cushing's apparent jealousy of his accomplishment. This widened the rift between them. Another source of irritation for Cushing was Dandy's refusal to join the Society of Neurological Surgeons (Cushing was a charter member). Dandy explained he could not spare the time and "they (the societies) were more social than beneficial." ${ }^{16}$

The final squabble between the two men happened in $1922 .{ }^{16}$ Dandy had just published in the Bulletin of Johns Hopkins Hospital about his dramatic improvement of Cushing's original contribution of partial enucleation of acoustic tumors. Dandy devised a new technique of total extirpation of the cerebellopontine angle tumor by suboccipital exposure and curettage, accomplished without bleeding or injury to the cranial nerves. Dandy did not give references in this publication, nor did he acknowledge Cushing's previous work in the field, since (he thought) this was just a preliminary report in the local bulletin and not a final paper. Cushing was very much annoyed and wrote a complaint to Smith, the director of Johns Hopkins Hospital:........II is extremely bad for me, inasmuch as many people know I had something to do with Dandy's training; It is equally bad for Dandy himself.....and it is very bad for Hopkins to have the Bulletin accept and permit the title of such an incomplete and promissory article to get into the literature ......" Cushing, however, did not send the letter to Smith. Instead, he sent it to Dandy with the following note..."I think you are doing yourself a great deal of harm by the tone of some of your publications. But you must not forget your manners, and this last note of yours is in extremely bad taste."

Dandy was of course, upset by this attack and immediately replied to his former mentor: "........While of course I am not unmindful of your inferences and taunts of dishonesty and your individual generalizations at various times, it has seemed better to ignore them....they do not reflect on you a great deal and in your position, you can ill afford it. ....... Doubtless, I should feel a keen resentment from such a letter, but I do not; I feel very sorry for one who is laboring under such an obsession...." He concluded his letter on a more respectful tone, thanking Cushing " whom I should look with greatest adoration and consider my friend, guide and master. ....It all seems so unnecessary. It should all be so different." ${ }^{16}$ Cushing's "vitriolic assault and Dandy's hard-hitting reply" 16 was the last episode of conflict between the two men.

\section{Dandy and Baseball Cap $^{17}$}

In 1941 Dandy, a lifelong baseball fan, devised a baseball cap with caps on the sides that could hold plastic pieces protective of the skull when the hitter is at bat. This was designed by Dandy, his wife and his two daughters on the dining table. He next collaborated with MacPhail of Brooklyn dodgers on the protective but, unfortunately, a 2-year fight for patent ensued between the two men. Dandy made clear his position that he was not as interested in financial gain as much as getting credit for his efforts. He did succeed when, in 1943, the patent was finally issued to Dandy. The cap is exhibited in the Baseball Hall of Fame in Cooperstown, NY.

\section{Dandy and His Family ${ }^{18}$}

Dandy was lucky to meet his future wife, Sadie Estelle Martin, a dietitian at Johns Hopkins, as they waited for an elevator at the hospital. They got married in 1923. Dandy was profuse in his praise of her in letters to his parents. They had four children, "Kiddies," Dandy called them. Walter Jr was born on their first wedding anniversary, Mary Ellen in 1927, Kathleen Louise in 1928, and Margaret in 1935.

The eldest daughter, Mary Ellen Marmaduke described Dandy as a loving husband and father, who gave immensely to his profession, enjoyed playing golf, tennis and bridge and was also an expert on the history of the American Civil War. She recalled how he would allow them to view his operations while he explained what he was doing. Dandy's son grew up to become an Anesthesiologist, establishing the first intensive care unit at Union Memorial Hospital in Baltimore.

Dandy was a prolific letter writer to his parents as well as to his own family. Sadie carefully preserved his letters. Mary Ellen and Kitty painstakingly transcribed them. These letters, numbering in hundreds, about Dandy's personal and family life document a close-knit family of "unselfish devotion," in the words of Kitty. They were gifted by the family to the Congress of Neurological Surgeons. They are available on the CNS website and are fascinating to read. ${ }^{5}$

\section{The Final Days ${ }^{18}$}

On April 1, 1946, Dandy was working with his youngest child, Margaret in their backyard, when he had to stop because of chest pain. He was hospitalized for coronary thrombosis but refused to believe the diagnosis. He self-diagnosed a gall bladder colic. Apparently, he did have some premonition of his end since he asked for his secretary to prepare his will. He signed it, with Professor Blalock and Doctor Frior as his witnesses. He did improve enough to go home and had several days with Sadie and all his children. He had a second attack from which he succumbed at Johns Hopkins Hospital, his alma mater, on April 19. His funeral services, attended by many friends and colleagues was held on April 22. Surgery., the distinguished journal, dedicated two volumes for "Dr Walter E. Dandy Birthday Number " in May and June of 1946 with introduction by Blalock and contributions from friends and admirers from US and abroad. ${ }^{19}$

The editorial in the Baltimore Evening Sun summarized well his contribution to neurological surgery: "He had imaginative genius to conceive of new and startling operative techniques, courage to try them, and skill, superb skill to make them successful." ${ }^{20}$

\section{Legacy Kept Alive}

The Walter E Dandy Neurosurgical Society was founded on November 19, 2011 in St. Louis, Missouri, Dandy's birthplace. The inaugural event was attended by Mary Ellen. The society has become the sole global representative for operative neurosurgery and became a forum for neurological surgeons. Multiple countries started their own chapters of the society to enhance the education of neurosurgical residents and medical students. ${ }^{21}$

Dandy's tale cannot be complete without talking about his eldest daughter and her contributions to neurosciences. ${ }^{22}$ After earning a Master's degree in Science Education at age 43, Mary Ellen developed in 1993-1999 an exhibit that was part of an NIH-funded Oregon Brainstorms Partnership Project. In the late 1990s, she joined an outreach organization of the Oregon Health \& Science University (OHSU) Brain Institute called "BRAINet,." She and other volunteers of BRAINet developed an educational presentation about neuroscience to the public.

In 2000, Mary Ellen was invited to speak at OHSU's Neuroscience Grand Rounds about her father, his life, and neurosurgery. For the next 15 years, she toured the country speaking at medical 
schools and conferences to lay audiences about her father and his contributions to medicine. She also became a friend and counselor to contemporary neurosurgeons.

In 2002, Mary Ellen wrote and published her book, "Walter Dandy: The Personal Side of a Premier Neurosurgeon." In 2015 she published a delightful article about her father "Walter Dandy: (1886-1946) A Personal Retrospective" with many charming pictures of the family. ${ }^{22}$ Mary Ellen Marmaduke died peacefully at home surrounded by her family on September $5,2017 .{ }^{22}$

\section{Author's Note}

The author is sometimes asked: why write about history? As he considered this question, several emotions were recalled: the curiosity of finding out why, what, who and how; the exhilaration of reading about the great medical discoveries and the personalities behind them; the wonder of their lives that shaped them to be the great thinkers and innovators. Having the luxury of time to delve into the circumstances that germinated the seeds of their investigation and that empowered them and also impeded them, the enthusiasm to share this excitement with colleagues was irresistible. Admittedly, there was nothing original here, just a review of the available literature of the subjects presented in a succinct and, hopefully, affable summary for the young surgeon inevitably short on leisure.

Arguably, there are valuable lessons that can be learnt from these inspiring tales. Consider, for example, the life history of Walter Dandy presented here. It is an account of a brilliant scientist and neurosurgeon, who was "twenty years ahead of all of his colleagues". ${ }^{23}$ Yet, he was a "reluctant hero" with all the human frailties of ego, impatience, obstinacy, and temper. ${ }^{23}$ It is worth being mindful about his infamous conflicts with his mentor Cushing, his intimate relationship with his parents, his dedication to his own profession and family and the hard task of balancing all of these with the demands of a pioneering career. In times of frustration with our own hectic schedules it is worth reflecting upon the grueling daily routine of his own and his residents.

As his biographer said, " He is truly a man of significance in medicine and history" and "a hero...to the young physicians and the many patients that came within his orbit." ${ }^{23}$ It is a privilege to learn about him and try to convey his story to the readers.

\section{OrCID}

Rao R Ivatury ๑ https://orcid.org/0000-0001-7208-7836

\section{References}

1. Walter Dandy-Wikipediahttps://en.wikipedia.org > wiki > Walter,_Dandy.

2. Fox WL: Dandy of Johns Hopkins. Baltimore: Williams \& Wilkins, 1984

3. Bhattacharyya KB. Walter Edward Dandy (1886-1946): The epitome of adroitness and dexterity in Neurosurgery. Neurol India 2018;66:304-307. DOI: 10.4103/0028-3886.227266

4. Sherman IJ, Ryan MK, Rafael JT. "Personal recollections of Walter E. Dandy and his brain team." J Neurosurg 2006;105(3):487-493. DOI: 10.3171/jns.2006.105.3.487

5. https://www.cns.org/meetings/past-honored-guests-detail/waltere-dandy-2

6. Corsello A, Dalmazi GD, Pani F, et al. Walter E. Dandy: his contributions to pituitary surgery in the context of the overall Johns Hopkins Hospital experience. Pituitary 2017; 20(6):683-691. DOI: 10.1007/s11102-017-0834-6.

7. Campbell E. Walter E. Dandy-Surgeon 1886-1946. J Neurosurg 1951;8(3):249-262. DOI: 10.3171/jns.1951.8.3.0249

8. Fox WL. Dandy of Johns Hopkins. Baltimore: Williams \& Wilkins, 1984 p24

9. Fox WL. Dandy of Johns Hopkins. Baltimore: Williams \& Wilkins, 1984 p25

10. Fox WL. Dandy of Johns Hopkins. Baltimore: Williams \& Wilkins, 1984 p36

11. Fox WL. Dandy of Johns Hopkins. Baltimore: Williams \& Wilkins, 1984 p 152

12. Fox WL. Dandy of Johns Hopkins. Baltimore: Williams \& Wilkins, 1984 p 154

13. Flamm MD, Eugene S. "New observations on the Dandy-Cushing controversy." Neurosurgery 1994;35(4):737-740.DOI: 10.1227/00006123199410000-00022

14. Patz MD, Laws ER, Thomas AJ: Cushing-Dandy Conflict-The Dandy Family Perception of the Discord. 4ww.neurosurgery-online.com

15. Goodrich JT. The Cushing-Dandy conflict-two powerful personalities that were best not to collide! Citation: World Neurosurg(2015);83 (1):11-12. DOI: 10.1016/j.wneu.2013.08.042

16. Fox WL. Dandy of Johns Hopkins . Baltimore: Williams \& Wilkins, 1984 pp 30-32, 46, 74-76

17. Fox WL. Dandy of Johns Hopkins . Baltimore: Williams \& Wilkins, 1984 p 204

18. Marmaduke MED. Walter dandy (1886-1946): a personal retrospective. Neurosurgery (2015);77(4):501

19. Fox WL. Dandy of Johns Hopkins . Baltimore: Williams \& Wilkins, 1984 p 221

20. Pearce JMS: Walter Edward Dandy 1886-1946 (2006). J Med Biogr 2006;14:(3)127-128.

21. https://wedns.org

22. In Memoriam: Mary Ellen Dandy Marmaduke,1927 to 2017 (2018). 82:2

23. Fox WL. Dandy of Johns Hopkins . Baltimore: Williams \& Wilkins, 1984 p 230 